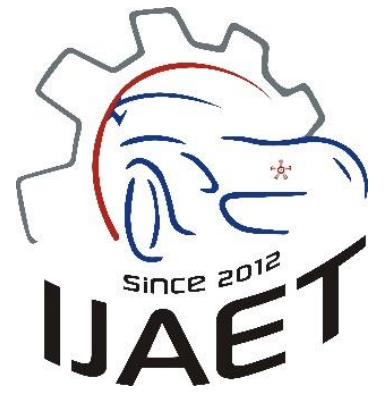

e-ISSN: 2146 - 9067

International Journal of Automotive

Engineering and Technologies

journal homepage: http://ijaet.academicpaper.org

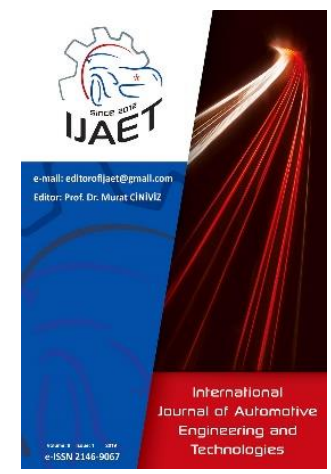

Original Research Article

\title{
Combustion Analysis of Biodiesel Derived from Bone Marrow in a Diesel Generator at Low Loads
}

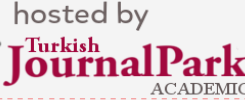

\section{Sinan Erdogan ${ }^{1, *}$, Mustafa Kemal Balki², Cenk Sayin ${ }^{3}$ \\ ${ }^{1}$ Ministry of Industry and Technology, KOSGEB, Marmara Directorate, Istanbul. Turkey \\ ${ }^{2}$ Department of Mechanical Engineering, Sinop University, Sinop, Turkey \\ ${ }^{3}$ Department of Mechanical Engineering, Marmara University, Istanbul, Turkey}

\section{ARTICLE INFO}

* Corresponding author

erdogan.sinan@gmail.com

Received: March 04, 2019

Accepted: Sep 11, 2019

Published by Editorial Board Members of IJAET

(C) This article is distributed by Turk Journal Park System under the CC 4.0 terms and conditions.

\begin{abstract}
In this study, biodiesel was produced from bone marrow by transesterification method. The vast majority of animal bones cannot be collected and recycled. This experimental study was carried out to incorporate unused resources in the economy. In this study, the effects of biodiesel produced from bone marrow on combustion characteristics of diesel engine were investigated. The B20 (mixing 20\% of biodiesel and 80\% diesel) and diesel (D2) were used as fuel in the tests. The tests were carried out at constant speed $(1500 \mathrm{rpm})$ and different engine loads ( $20 \%$ and $40 \%$ of the maximum power output) of a diesel engine with direct injection, four-cylinder, and four-stroke. The combustion characteristics of the engine, such as cylinder gas pressure, heat release rate, cumulative heat release, and mean gas temperature were determined using combustion analysis software (FEBRIS) under 3.6 and $7.2 \mathrm{~kW}$ loads. The maximum points of cylinder gas pressures have been very close in both fuels (D2, B20) at the $3.6 \mathrm{~kW}$ power output. The peak pressure of the B20 raised with the increase of the engine load. The oxygen in the content and higher cetane number of the biodiesel has raised the peak point of the heat release rate. Keywords: Alternative fuels, Biodiesel from bone marrow; Diesel engine, Combustion characteristics.
\end{abstract}

\section{Introduction}

Biodiesel fuels obtained from vegetable and animal oils give similar results to diesel fuel in terms of combustion characteristics. At the same time, biodiesel fuels are more environmentally friendly. Due to this situation, biodiesel has an important place among alternative energy sources. Biodiesel fuels have different chemical structure and fuel properties depending on the content and production method. For this reason, the combustion characteristics such as the pressure increase rate and the ignition delay vary depending on the fuel characteristics of the biodiesel. In an internal combustion engine, vibration occurs due to sudden pressure differences during combustion. At the same time, the inertia forces formed by changes in the acceleration of the motor parts in the linear and circular motion also generate vibrations [1]. Vibrations exceeding certain levels will result in a reduction in engine life over the long term. The noise brought about by vibrations also has negative effects on driving comfort and human health. The most important reason for vibration and noise in the 
engine is the combustion. For this reason, fuel type is one of the parameters that affect vibration and noise.

The amount of fuel entering into the combustion chamber at the time of prolonged ignition delay increases and the amount of energy in the combustion chamber suddenly rises when the fuel starts to burn. This sudden increase in energy will cause rapid pressure rises. In the event of uncontrolled ignition, combustion in the cylinder cannot develop perfectly. As a result, it creates a knock on diesel engines [2]. The maximum acceptable pressure increase rate is $10 \mathrm{bar} /{ }^{\circ} \mathrm{CA}$. In order to avoid this limit, the ignition delay must be reduced [3].

In literature, there are some studies examining the combustion characteristics of biodiesel fuels, knock and noise densities. Gürü et al. [4] have examined that the cylinder pressure peak of biodiesel obtained from waste chicken oil is higher than that of diesel fuel, and the pressure rise of biodiesel has carried out earlier than diesel. Selvam and Vadivel [5] obtained waste pork lard methyl ester from inedible animal tallow by base-catalyzed transesterification with methanol in the presence of potassium hydroxide $(\mathrm{KOH})$ as a catalyst. In their engine tests of B25 fuel at $1500 \mathrm{rpm}$ engine speed, under $20 \%$ and $40 \%$ loads, the maximum cylinder pressure of the B25 was measured higher than that of diesel. Alptekin et al. [6] used biodiesel derived from fleshing oil biodiesel in a direct injection diesel engine. According to combustion results, fleshing oil biodiesel started to burn earlier than diesel because of higher cetane number of fleshing oil biodiesel. Maximum cylinder gas pressure of the biodiesel was higher than that of diesel generally while maximum cylinder gas pressure of B20 fuel blend was close to diesel. Awad et al. [7] tested biodiesel obtained from animal wastes in a diesel engine with a single cylinder, air cooled at $1500 \mathrm{rpm}$ engine speed under $20 \%$ load. The maximum pressure of biodiesel was higher than diesel under low load. Gharehghani et al. [8] investigated combustion characteristics of a biodiesel fuel produced from waste fish oil. The maximum in-cylinder pressure and heat release rate of the biodiesel were higher than diesel under $50 \%$ engine load. In addition, the heat release rate started earlier for the biodiesel blends cases. Uludamar et al. [9] studied the effects of biodiesel-standard diesel fuel mixtures on the vibration of the engine. In their study, it was stated that biodiesel fuel mixtures decreased engine vibration and noise. Sarıdemir et al. [10] stated that B10 fuel had a higher knock intensity. It also revealed that there was a simultaneous increase in the maximum pressure increase rate and knock intensity. There are very limited studies on the production of fuel using bone marrow fat. In a study, Didar [11] produced biodiesel from waste beef bone fat via two-stage acid-base transesterification in an experimental study. The last stage transesterification reaction of beef bone fat was carried out using 30:1 molar of ethanol to fat in the presence of $1 \%$ sulfuric acid at $78^{\circ} \mathrm{C}$.

In this study, the combustion characteristics of fuel mixtures diesel and biodiesel obtained from bone marrow were investigated. When the literature is examined, it is seen that there is a very limited number of studies in which the biodiesel obtained from beef bone marrow is used as fuel. The beef bone marrow is one of the largest wastes in the gelatin production industry. However, only a small proportion of the waste bones are recycled in the industry. The aim of this study is to encourage the introduction of animal wastes into the economy.

\section{Materials and Methods}

\subsection{The engine test procedures}

In the experiments, it was used a diesel engine which was direct injection, four-cylinder, four stroke, water cooled, naturally aspirated, and $2270 \mathrm{cc}$. The engine's compression ratio is 17:1, and maximum power output is $18 \mathrm{~kW}$. The specifications of the diesel generator set presented in Table 1.

The tests were carried out at $3.6 \mathrm{~kW}$ (\%20 of the maximum power output) and $7.2 \mathrm{~kW}(\% 40)$ loads while the engine was running at $1500 \mathrm{rpm}$. In order to load the engine, the electrical resistance unit was used. A schematic diagram of the test set-up is shown in Fig. 1.

The tests were performed using the Febris combustion analysis software that records the signals received from the fiber-optic pressure sensor inside the engine cylinder and the crank angle sensor in real time [12].

A fiber-optic pressure sensor, Optrand D33294$\mathrm{Q}$ (1.35 $\mathrm{mV} / \mathrm{psi}$ precision) was used for cylinder gas pressure measurement. 
Table 1. The specifications of the diesel generator set

\begin{tabular}{ll}
\hline Parameters & Specifications \\
\hline Engine brand and model & Fawde 4DW81-23D \\
Number of cylinder & 4 \\
Engine speed & $1500 \mathrm{rpm}$ \\
Bore and stroke & $85 \times 100 \mathrm{~mm}$ \\
Displacement & $2400 \mathrm{cc}$ \\
Compression ratio & $17: 1$ \\
Power output & $18 \mathrm{~kW}$ \\
Number of injection nozzle & 4 \\
Nozzle opening pressure & $400 \mathrm{bar}$ \\
Injection timing & $23^{\circ} \mathrm{bTDC}$ \\
Generator brand and model & $\mathrm{Newpower} \mathrm{NWR} \mathrm{22}$ \\
Standby power & $17.5 \mathrm{~kW}$ \\
Prime power & $16 \mathrm{~kW}$ \\
Power factor & 0.8 \\
Frequency & $50 \mathrm{~Hz}$ \\
\hline
\end{tabular}

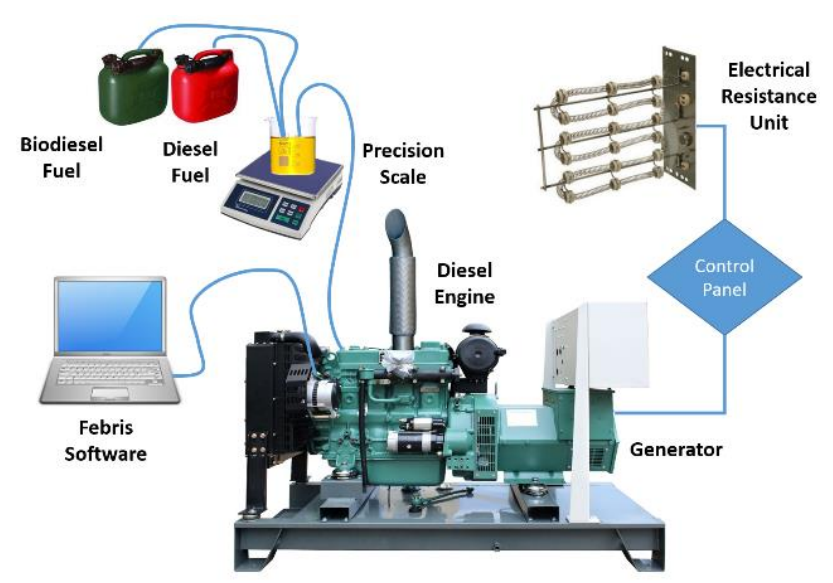

Fig. 1. Diesel generator set and test set-up.

Table 2. The properties of the test fuels

\begin{tabular}{|c|c|c|c|}
\hline Property & D2 & B20 & $\begin{array}{l}\text { Biodiesel } \\
\text { Standards } \\
\text { ASTM D6751 } \\
\text { EN 14214 }^{\mathrm{b}}\end{array}$ \\
\hline $\begin{array}{l}\text { Kinematic } \\
\text { viscosity }\left(\mathrm{mm}^{2} / \mathrm{s}\right)\end{array}$ & 2.80 & 3.79 & $\begin{array}{l}1.9-6.0^{\mathrm{a}} \\
3.5-5.0^{\mathrm{b}}\end{array}$ \\
\hline $\begin{array}{l}\text { Density } \\
\left(\mathrm{kg} / \mathrm{m}^{3} \text { at } 20^{\circ} \mathrm{C}\right)\end{array}$ & 840 & 848.6 & $\begin{array}{l}-^{a} \\
860-900^{b}\end{array}$ \\
\hline $\begin{array}{l}\text { Lower heating } \\
\text { value }(\mathrm{MJ} / \mathrm{kg})\end{array}$ & 43.3 & 42.8 & $-\mathbf{a , b}$ \\
\hline Cetane number & 52 & 53 & $\begin{array}{l}47 \min ^{\mathrm{a}} \\
51 \min ^{\mathrm{b}}\end{array}$ \\
\hline $\begin{array}{l}\text { Iodine number } \\
(\mathrm{gI} / 100 \mathrm{gr})\end{array}$ & 0 & 8 & $-^{\mathrm{a}}$ \\
\hline $\begin{array}{l}\text { Flashing point } \\
\left({ }^{\circ} \mathrm{C}\right)\end{array}$ & 78 & 94.7 & $\begin{array}{l}93 \min ^{a} \\
101 \min ^{b}\end{array}$ \\
\hline
\end{tabular}

Depending on the crank angle, cylinder pressure values were obtained by the sensor. The raw pressure data inlet cylinder was processed and parameters such as net heat release rate, and cumulative net heat release were calculated by the software.

In this study, the transesterification method was preferred to produce biodiesel from bone marrow. Biodiesel was produced by using sodium hydroxide as a catalyst and methanol as alcohol, at $60^{\circ} \mathrm{C}$ throughout 3 hours for this experimental study. This bone fat has been preferred because it is a low-cost alternative like non-edible feedstock. D2 (\%100 commercial diesel), and B20 (\%20 biodiesel from bone marrow, \%80 commercial diesel) fuel blends were used in the experiments. Their physical and chemical properties were measured at TUBITAK Marmara Research Center and presented in Table 2.

\section{Results and Discussion}

In this study, tests were carried out at a constant engine speed of $1500 \mathrm{rpm}$ under engine loads of $3.6 \mathrm{~kW}$ and $7.2 \mathrm{~kW}$. By using cylinder gas pressure data, the cumulative net heat release, net heat release rate, and mean gas temperature were calculated by FEBRIS software.

The cylinder gas pressure is a parameter that characterizes combustion capability and shows the quality of the mixture of air-fuel. It is seen the variations of the cylinder gas pressures of the fuels under $3.6 \mathrm{~kW}$ and $7.2 \mathrm{~kW}$ loads according to the crank angle in Fig. 2 and Fig. 3.

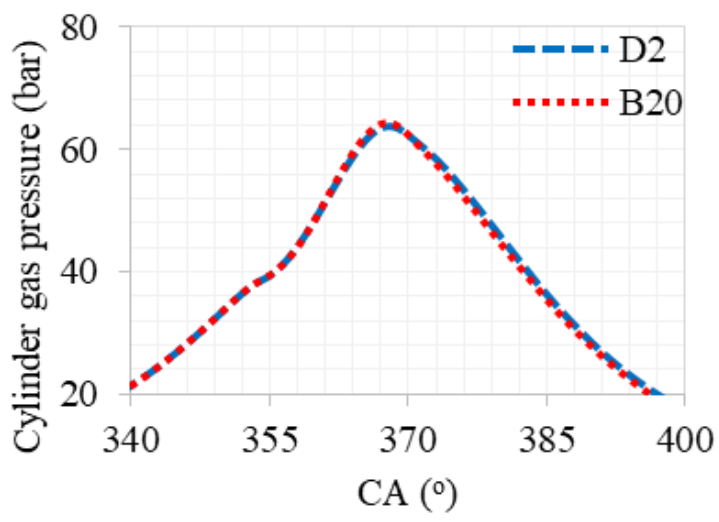

Fig 2. The variations of the cylinder gas pressures at 3.6 $\mathrm{kW}$ power output.

The maximum cylinder gas pressure is increased when the rate of burned fuel increases at the premixed combustion phase in a compressionignition engine. In this process, the viscosity and volatility of the fuel have a very important role [13].

In the tests, B20 at $3.6 \mathrm{~kW}$ load shows similar combustion characteristics with D2. The maximum cylinder gas pressure values of D2 and B20 are 63.8 bar and 64.2 bar respectively. The maximum cylinder gas pressure was 
realized in the two fuels $8{ }^{\circ} \mathrm{CA}$ after TDC (top dead center). It is stated that high viscosity of biodiesel accelerates spraying process. This leads to the change of the start of combustion [14].

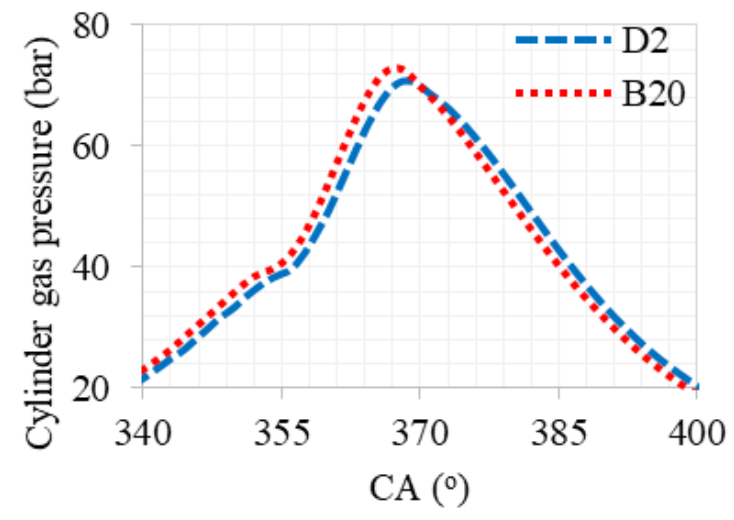

Fig 3. The variations of the cylinder gas pressures at 7.2 $\mathrm{kW}$ power output.

In the premixed combustion phase, suddenly pressure rises and high maximum cylinder gas pressure are occurred because of a high rate of burned fuel at $7.2 \mathrm{~kW}$ engine load. The maximum cylinder gas pressure of D2 is 70.8 bar and the B20 fuel is 73.0 bar. The peak points of D2 and B20 has been $9^{\circ}$ and $7^{\circ} \mathrm{CA}$ after TDC. Due to the high viscosity of B20, the injector nozzle is opened earlier than the D2 fuel. In addition, the high cetane number of B20 has contributed to the high maximum cylinder gas pressure. In a study, it was stated that the maximum cylinder gas pressure of biodiesel obtained from animal fat residues was higher than that of diesel in tests carried out under $20 \%$ load [7]. Similar results were obtained in a study using biodiesel obtained from methyl esters of chicken oil and waste pork lard [4, 5]. The higher the density of B20 compared to the D2, the more fuel is burned and the more energy is produced. Besides, the presence of oxygen in the content of B20 contributes to a better combustion.

The heat release rate is a function of the cylinder gas pressure. It is calculated with equations according to instantaneous changes in pressure. These equations are given in the Appendix. The heat release rates of the fuels are shown in Fig. 4 and Fig. 5 at low loads. The D2 and B20 fuels showed very similar tendency to heat release rate at $3.6 \mathrm{~kW}$. There is a decrease in heat dissipation prior to the start of heat release. This is due to the decrease in the temperature value as a result of absorbing heat in the environment to evaporate the sprayed fuel.

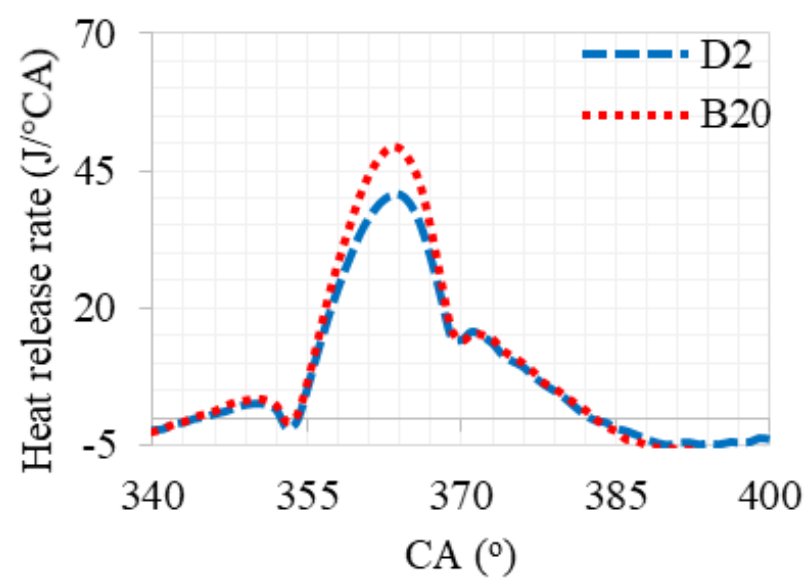

Fig 4. The variations of the heat release rates at $3.6 \mathrm{~kW}$ power output.

Under $3.6 \mathrm{~kW}$ load, the static ignition delay of B20 is lower than that of D2. Static ignition delay is found $16.7^{\circ} \mathrm{CA}$ when using $\mathrm{D} 2$ fuel and it is found $16^{\circ} \mathrm{CA}$ when using B20. The higher the cetane number of $\mathrm{B} 20$ has been effective in maximizing the peak point of the heat release rate. The maximum heat release rate of $\mathrm{D} 2$ is $41.8 \mathrm{~J} /{ }^{\circ} \mathrm{CA}$ and the $\mathrm{B} 20$ fuel is $50.2 \mathrm{~J} /{ }^{\circ} \mathrm{CA}$.

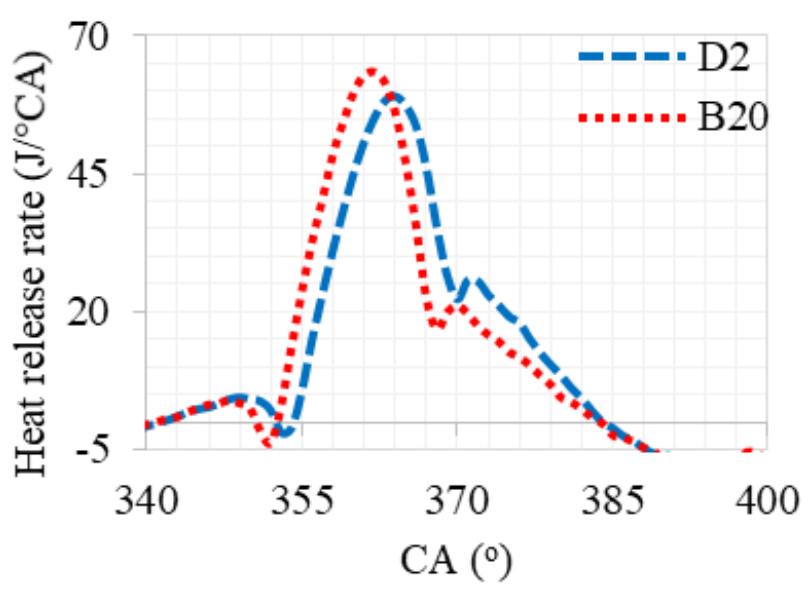

Fig 5. The variations of the heat release rates at $7.2 \mathrm{~kW}$ power output.

Under the $7.2 \mathrm{~kW}$ load, it sent more fuel into the cylinders, and more energy has been consumed. In this case, maximum heat release rates have also increased. The maximum heat release rates of D2 and B20 are $60 \mathrm{~J} /{ }^{\circ} \mathrm{CA}$ and $63.3 \mathrm{~J} /{ }^{\circ} \mathrm{CA}$, respectively. Static ignition delay is found $16.3^{\circ}$ CA when using D2 fuel and it is found $15.5^{\circ} \mathrm{CA}$ when using B20 at the $7.2 \mathrm{~kW}$. As seen in Fig. 5 the combustion for B20 has started earlier approximately $2^{\circ} \mathrm{CA}$.

Fig. 6 and Fig. 7 show the cumulative heat release of the fuels at the power output of 3.6 $\mathrm{kW}$ and $7.2 \mathrm{~kW}$. The cumulative heat release 
rates can be used to determine ignition delay, combustion start, end of combustion and combustion times in the combustion analysis.

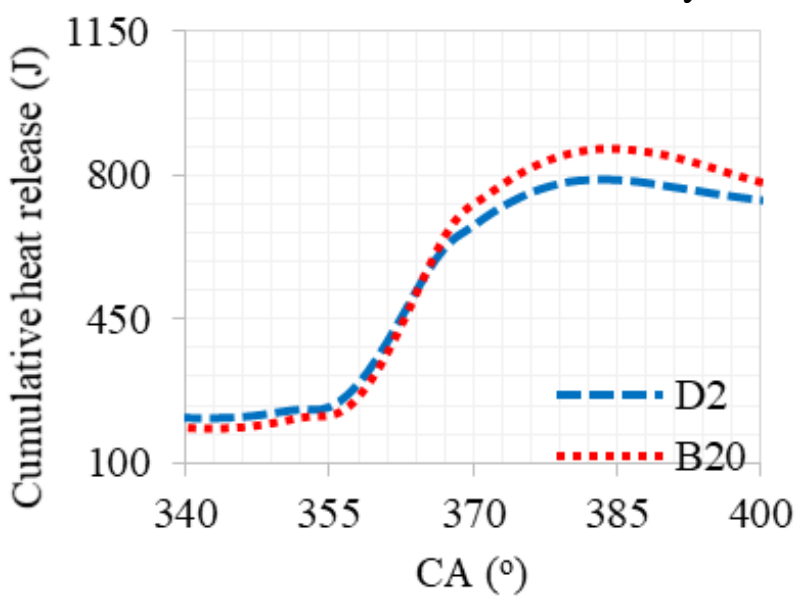

Fig 6. The variations of the cumulative heat release at $3.6 \mathrm{~kW}$ power output.

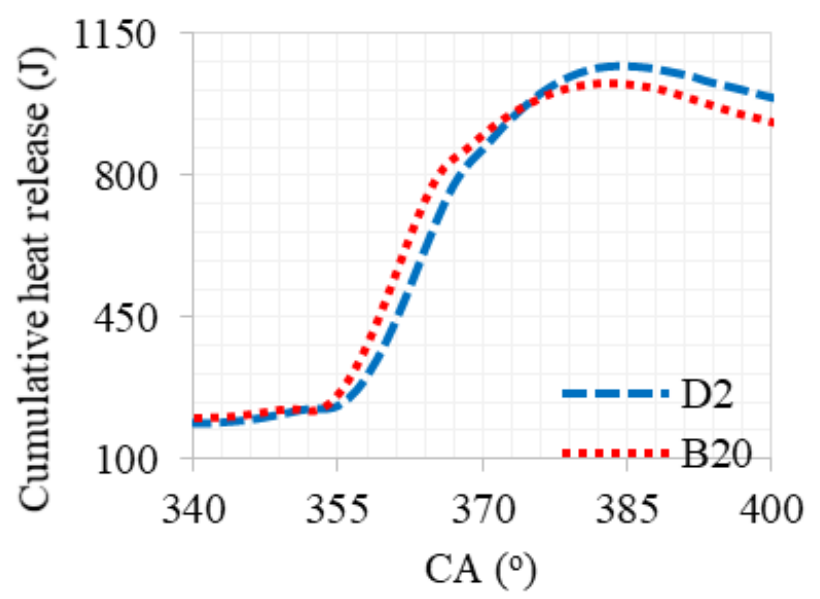

Fig 7. The variations of the cumulative heat release at $7.2 \mathrm{~kW}$ power output.

The air-fuel mixture is homogenized more slowly due to the viscosity of B20. For this reason, the combustion duration of B20 is longer than D2. With the prolonged burning time, the amount of burned fuel in the cylinder increases, thus increasing the amount of heat release.

Because of the high oxygen and ignition ability of the biodiesel, the combustion start of B20 was earlier than D2 at $7.2 \mathrm{~kW}$. When the B20 fuel was used, the combustion of more fuel during the premixed combustion phase led to the burning of less fuel in the controlled combustion phase. This leads to a shortening of the B20 combustion duration and a reduction in the peak of the cumulative heat release. According to the results of the tests, the maximum heat release amounts of D2 and B20 are $1073 \mathrm{~J}$ and $1027 \mathrm{~J}$, respectively.

Fig. 8 and Fig. 9 show the variation of the mean gas temperatures of the fuels according to the crank angle in the $3.6 \mathrm{~kW}$ and $7.2 \mathrm{~kW}$ power output.

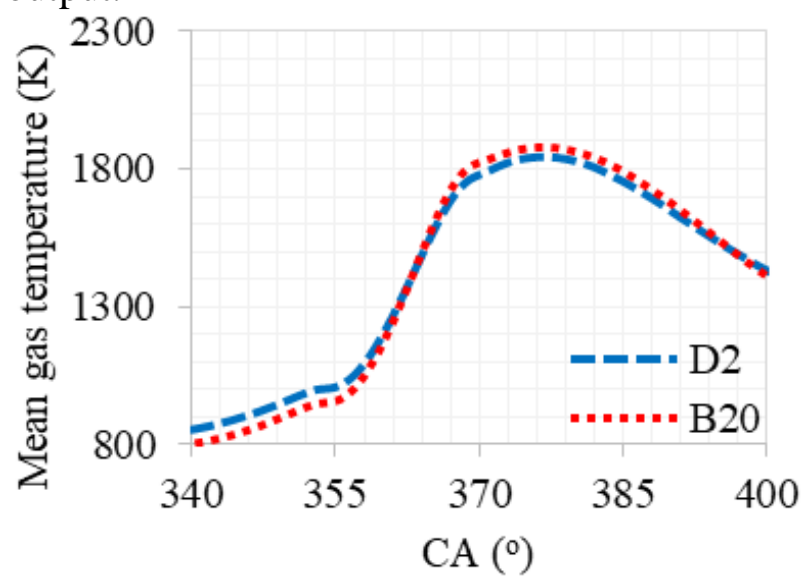

Fig 8. The variations of the mean gas temperature at 3.6 $\mathrm{kW}$ power output.

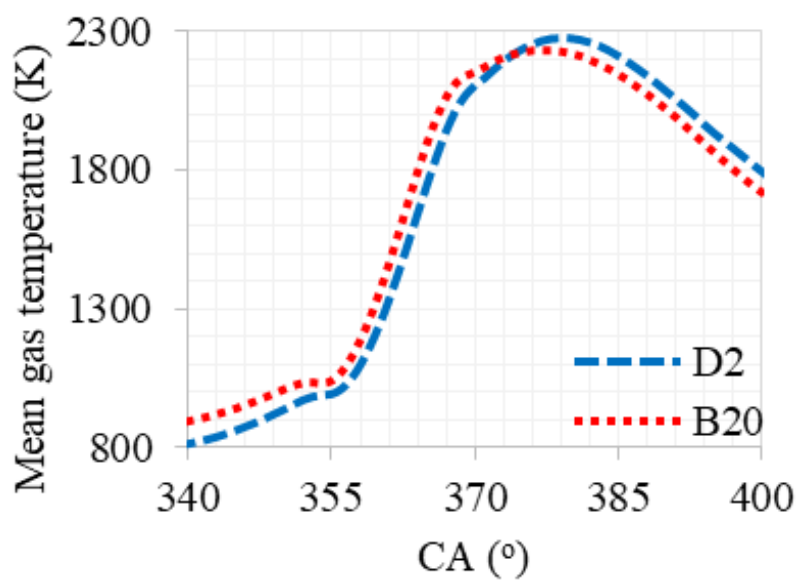

Fig 9. The variations of the mean gas temperature at 7.2 $\mathrm{kW}$ power output.

The graphs of the mean gas temperature show a similar trend with the cumulative heat release graphs. The maximum mean gas temperature of the B20 has been higher than D2 at $3.6 \mathrm{~kW}$ power output because of the improvement of the combustion with the oxygen contained in the biodiesel. Another reason for the high value of B20 is that the combustion durations of the two fuels are very close to each other. The maximum mean gas temperature values of D2 and B20 respectively are $1847 \mathrm{~K}$ and $1877 \mathrm{~K}$ under 3.6 kW load.

The maximum mean gas temperature of B20 is lower than D2 at $7.2 \mathrm{~kW}$ due to the early start of combustion and the shortening of the combustion time. The maximum mean gas temperature values are $2275 \mathrm{~K}$ in D2, and 2234 $\mathrm{K}$ in $\mathrm{B} 20$.

\section{Conclusions}

In the experimental study, biodiesel produced from bone marrow was investigated in internal 
combustion engines. The results can be listed as follows.

- Cylinder gas pressures showed similar tendencies in both fuels (D2, B20), the maximum points of cylinder gas pressures were very close at the $3.6 \mathrm{~kW}$ engine load.

- B20 fuel has a 3\% higher maximum cylinder gas pressure compared to D2 at the 7.2 $\mathrm{kW}$ engine load. Due to the high viscosity of the B20, $2{ }^{\circ} \mathrm{CA}$ have been previously opened according to the injector nozzle D2.

- $\quad$ The higher cetane number of B20 has affected the peak point of the heat release rate. The maximum point of B20 is increased by $20 \%$ compared to D2 at the $3.6 \mathrm{~kW}$. Due to the high density of the B20, more fuel was injected into the cylinder.

- The peak heat release rate of B20 increased by $6 \%$ to $\mathrm{D} 2$, and $2{ }^{\circ} \mathrm{CA}$ were realized early.

- $\quad$ The mean gas temperature of B20 has been slightly higher than that of D2 due to the same combustion duration of both fuels under $3.6 \mathrm{~kW}$. Another factor affecting this increase is that oxygen in the biodiesel improves combustion.

- When B20 has used, the majority of the fuel that sprayed has already exhausted due to the earlier start of combustion. This situation caused the mean gas temperature of B20 to be slightly lower than the peak of D2 at $7.2 \mathrm{~kW}$.

This study has been prepared in order to bring the animal wastes to the economy and to create new resources. Although some of the animal wastes are edible, they are cheaper than vegetable oils. For example, approximately 15 million cattle are consumed annually in Turkey. A very small portion of these animals' bones can be collected and recycled. Biodiesel produced from waste beef bone marrow represents a lowcost alternative like non-edible feedstocks. Beef bone marrow is one of the major wastes from gelatin production industry. If the usability of the fuel obtained from the bone marrow is acceptable, there will also become important the remaining from uncollected bone marrow. In this way, the number of usage areas of waste bone marrow will increase.

\section{Appendix}

The mean gas temperature, specific heat ratio, net heat release rate, and cumulative net heat release were calculated via FEBRIS software by using the cylinder gas pressure and position of crank angle degree. The cylinder gas pressures obtained from 100 cycles were averaged in order to decrease the influence of cycle-by-cycle changing.

The mean gas temperature is determined from the Eq. (1) derived from ideal gas law [15].

$T_{i}=P_{i} V_{i} \frac{T_{\text {ref }}}{P_{\text {ref }} \cdot V_{\text {ref }}} \quad$ Eq. 1

where, $T_{r e f}, P_{r e f}$ and $V_{r e f}$ are reference values at any point of polytrophic curve of expansion. $T_{i}$, $P_{i}$ and $V_{i}$ are mean gas temperature, pressure and cylinder volume respectively.

The specific heat ratio is calculated as in Eq. (2) depending on the mean gas temperature based on the experimental studies of Brunt [16].

$\gamma=1.338-60 \times 10^{-5} T+1 \times 10^{-8} T^{2}$ Eq. 2

Net HRR was calculated via the ideal gas law and first law of thermodynamics as in Eq. (3).

$\frac{d Q_{\text {net }}}{d \theta}=\frac{\gamma}{\gamma-1} p \frac{d V}{d \theta}+\frac{1}{\gamma-1} V \frac{d p}{d \theta} \quad$ Eq. 3

Cumulative net heat release is also calculated by integrating net HRR as seen Eq. (4) [15].

$\int d Q_{n e t}=\int\left(\frac{\gamma}{\gamma-1}\right) p(d V)+\left(\frac{1}{\gamma-1}\right) V(d p)$

Eq. 4

where $\gamma$ is the ratio of specific heats which ranges from 1.25 to 1.34 according to values obtained by Eq. (2), $\theta$ is crank angle, $p$ is inlet cylinder gas pressure, and $V$ is cylinder volume.

\section{References}

1. J.B. Heywood. Internal combustion engine fundamentals. Mcgraw-Hill New York (1988).

2. A. Taghizadeh-Alisaraei, B. Ghobadian, T. Tavakoli-Hashjin, S.S. Mohtasebi. Vibration analysis of a diesel engine using biodiesel and petrodiesel fuel blends. Fuel. 102 (2012) 41422.

3. B. Safgönül, M. Ergeneman, H.E. Arslan, C. Soruşbay. İçten yanmalı motorlar. Birsen Yayınevi (2013).

4. M. Gürü, A. Koca, Ö. Can, C. Çınar, F. Şahin. Biodiesel production from waste chicken fat based sources and evaluation with $\mathrm{Mg}$ based additive in a diesel engine. Renew Energ. 35 (2010) 637-43.

5. D.J.P. Selvam, K. Vadivel. An experimental investigation on performance, emission, and combustion characteristics of a diesel engine fueled with methyl esters of waste 
pork lard and diesel blends. Int J Green Energy. 10 (2013) 908-23.

6. E. Alptekin, M. Canakci, A.N. Ozsezen, A. Turkcan, H. Sanli. Using waste animal fat based biodiesels-bioethanol-diesel fuel blends in a DI diesel engine. Fuel. 157 (2015) 245-54.

7. S. Awad, K. Loubar, M. Tazerout. Experimental investigation on the combustion, performance and pollutant emissions of biodiesel from animal fat residues on a direct injection diesel engine. Energy. 69 (2014) 82636.

8. A. Gharehghani, M. Mirsalim, R. Hosseini. Effects of waste fish oil biodiesel on diesel engine combustion characteristics and emission. Renew Energ. 101 (2017) 930-6.

9. E. Uludamar, E. Tosun, K. Aydin. Experimental and regression analysis of noise and vibration of a compression ignition engine fuelled with various biodiesels. Fuel. 177 (2016) 326-33.

10. S. Saridemir, N. Alcelik, I. Uygur. Investigating the effect of biodiesel and petrodiesel fuel blends on diesel engine vibration. Electronic Journal of Machine Technologies. 13 (2016) 103-10.

11. Z. Didar. A comparative study of biodiesel production from beef bone marrow. Journal of Food Biosciences and Technology. 5 (2015) 61-6.

12. S. Aydin, C. Sayın. Impact of thermal barrier coating application on the combustion, performance and emissions of a diesel engine fueled with waste cooking oil biodiesel-diesel blends. Fuel. 136 (2014) 334-40.

13. A. Ramadhas, S. Jayaraj, C. Muraleedharan. Characterization and effect of using rubber seed oil as fuel in the compression ignition engines. Renew Energ. 30 (2005) 795803.

14. M. Shahabuddin, A. Liaquat, $H$. Masjuki, M. Kalam, M. Mofijur. Ignition delay, combustion and emission characteristics of diesel engine fueled with biodiesel. Renew Sust Energ Rev. 21 (2013) 623-32.

15. G.P. Merker, C. Schwarz, R. Teichmann. Combustion engines development: mixture formation, combustion, emissions and simulation. Springer Science \& Business Media (2011).

16. M.F. Brunt, K.C. Platts. Calculation of heat release in direct injection diesel engines.
SAE transactions. (1999) 161-75. 